\title{
Tema 7. El docente y la construcción de la autoridad
}

\section{Presentación}

Uno de los espacios que más incide en la formación del niño es la escuela, y precisamente dentro de esta el educador desempeña un papel primordial en la medida en que se convierte en uno de los modelos del niño e interviene sobre él por medio de los actos pedagógicos, los actos de habla y las conductas que este puede llegar a imitar. Centrarnos en el tema de la relación educador-niño nos sitúa en el marco del quehacer educativo, en la formación de la pisque infantil y de sus bases como ciudadano.

\section{Propósito (objetivo)}

Posibilitar al docente y al padre de familia la identificación de los principales elementos que se dinamizan en la relación educador-niño, con el fin de que estos puedan debatirse y asimilarse dentro del quehacer y en la comunidad educativa en la que está inmerso el niño. 


\section{Conceptualización general}

Hay una serie de elementos esenciales en la relación entre el educador y el niño, entre ellos la autoridad de la palabra que tiene el educador, el reconocimiento de la historia del niño, la función de modelamiento o de identificación del educador, y el manejo de la empatía que media dicha relación.

A lo largo del tiempo la percepción sobre la autoridad del educador y la historia del niño como sujeto de sus propios deseos ha cambiado. Para la tradición del pensamiento medieval la palabra del educador era indubitable bajo el "principio de autoridad" y el aprendiz se circunscribía en un respetuoso acto de fe; sin embargo, tiempo después Descartes introdujo la duda metódica, que favoreció el naciente principio de incertidumbre sobre los argumentos.

Así, primero se tiene que advertir que el posicionamiento de cada sujeto ante la autoridad está marcado por su historia ante la misma, lo cual implica que si el educador es representante de la autoridad, frente a esta representación las posiciones de los alumnos pueden ser múltiples y variadas, desde muy temprana edad, ya sea que la acepten, negocien su posición, la rechacen, se burlen de ella, la transgredan o la ataquen. Es aquí donde es primordial la empatía, pues gracias a ella el alumno transfiere hacia el maestro afectos que se originan de sus relaciones afectivas primarias, con los cuales acepta o rechaza al educador y viceversa; el educador pone en el estudiante sus patrones afectivos.

A pesar de la dimensión de amor y de rechazo de la relación del educador con el alumno, aquel no puede dejar de cumplir su función educativa, por eso,

Ubicarse como maestro frente a un grupo de sujetos implica entonces que cada uno de ellos es sujeto de su historia, y que sus palabras afectarán a cada uno de ellos de una forma diferente, de manera que asumir una posición frente a cada uno, es ser uno más con su historia, en una relación de sujetos diferentes, donde el profesor irremediablemente actuará respetando esa diferencia. (Ríos, 1993, p. 10)

Si el educador busca contribuir a la formación del niño no puede asumir la autoridad como autoritarismo — creer que él es la autoridad, 
imponer sus deseos, como el poder que domina y que coacciona-, más bien se le invita a representar la autoridad como una construcción desde la cual adquiere respeto, admiración y prestigio, pero especialmente como una instancia que legitima un acto pedagógico diferente con cada estudiante, un acto de habla a la "medida" de las necesidades de cada alumno, pues no podrá actuar igual con todos; si lo hiciera estaría evadiendo su responsabilidad formativa, sería solo un instructor y no un maestro. Esto de plano descarta, aunque algunos así lo crean, que la autoridad del docente se encuentra solo en poner una nota, y que es sinónimo del poder de calificar y descalificar.

\section{La construcción de la autoridad}

La autoridad del educador es un instrumento que le permite manejar con empatía los afectos —amor y odio- que depositan en él sus alumnos, también consiste en saber responder a ese ideal que representa para los niños, a pesar de sus preferencias y de su propia historia personal.

Así, la autoridad surge como un constructo que obedece a distintos componentes de su vocación, entre ellos el poder, la jerarquía, la normatividad, la disciplina y la obediencia, que se originan de aquella posición de ideal del yo en el cual el estudiante ubica al educador, y que a su vez será un soporte para desarrollar la ética civil y ciudadana del niño.

En este constructo, como ideal, el representa un poder, que no se entiende como la acostumbrada coacción sino como la capacidad de hacer potente, de explotar las potencialidades; la jerarquía entre él y el alumno no se ve como una organización arbitraria sino como la apropiada distribución de responsabilidades, fruto de un reconocimiento de la experiencia. La norma deja de concebirse como restricción o presión, para comprenderse como un conjunto de deberes y de derechos que regulan la cooperación entre los miembros de la comunidad escolar. La disciplina, entonces, se desmiente como régimen autoritario para transformarse en conciencia de orden, autodisciplina o autonomía de una voluntad libre.

Tales elementos se aúnan en la palabra trabajo. Solo el trabajo del educador le otorga autoridad, como un reconocimiento desde el otro, y es propiamente este reconocimiento el que se modela como ejemplo 
para el niño. El trabajo incluye el poder que hace surgir las potencialidades, la responsabilidad, la cooperación, la dignidad, la reputación y la disciplina. Así, la noción de autoridad es fruto de la labor de cada sujeto en su entorno social y del reconocimiento mutuo, consecuencia de la interacción social, en la que cada uno se esfuerza por desempeñar bien el rol que le compete, como educador, como padre, como ciudadano.

Por ende, el profesor obtiene la autoridad de su actitud de trabajo, no la ejerce como un don autoritario, la realiza o la produce desde su mismo modo de ser, desde su talante para la vida. Desde esta perspectiva, la autoridad se convierte en terreno abonado para el proceso de construcción de la interlocución, en el sentido que le da Lyotard (1994), como un proceso en el que cada hombre debe adquirir el derecho a hablar, pasar a través de la inexperiencia de un lenguaje o código a su posterior aprendizaje.

Estas dos posiciones las define Lyotard como la del tú y la del yo. El tú es un alumno, es un yo en suspensión, un silencioso y disciplinado aprendiz - lo cual no quiere decir que no busque saber o que no indague-, significa que se encuentra en una clase de escucha activa; tal actitud, su silencio disciplinado, tiene como posterior recompensa el hablar autorizado, su transformación en un yo. Este es el principio básico de la interlocución, según Lyotard, en la cual el que enseña no se autoriza despóticamente, sino que debe estar autorizado por el que escucha, para que posteriormente este, el tú, pueda decir algo con autonomía, ser un yo.

Para esto sirve la autoridad del educador, para fundamentar la interlocución con el niño, independientemente de su nivel cognitivo y lingüístico, siempre debe abrirse el espacio para la manifestación de sus palabras, darle un lugar en la historia propia, del profesor, de su grupo y de la escuela. Interlocución es el otro modo de nombrar el manejo de la transferencia de los afectos del alumno hacia el profesor, y de paso, del profesor al alumno. Interlocución traducida especialmente en preguntas que manifiesten interés y respeto por la posición del alumno — cualquiera que esta sea- y comentarios o estímulos verbales acordes con las motivaciones de cada niño, pues no solo hay que estimular el logro, sino principalmente las motivaciones, elecciones y el interés del niño. La interlocución es, pues, el fundamento de la ciudadanía deliberativa, ciudadanía con capacidad de participar y hablar. 


\section{Acercamiento personal (reflexión)}

- ¿Se ha encontrado en la institución educativa, en alguna ocasión, una manifestación de amor o de enojo por parte de algún alumno o de sus padres? ¿Qué hizo en esa situación?

- ¿Cómo cree que se puede orientar, a través de una adecuada empatía, la rivalidad del alumno hacia el maestro o la rivalidad de los maestros hacia los padres?

\section{Actividades sugeridas}

Búsquedas en Internet y bibliotecas

Búsquedas de casos en prensa
- Busque y defina qué es el abuso de autoridad por parte de un docente y qué es abuso de autoridad por parte de los padres.

- Explore qué sucede con el alumno cuando está cerrada la vía del diálogo entre él y su educador. ¿Qué puede suceder entre el docente y el padre de familia del niño si el estudiante se siente excluido o ve preferencias del docente hacia otros compañeros? ¿Cómo se puede resolver el conflicto que surge de esa situación?

- Busque en prensa casos en los cuales los docentes han hecho parte o no han actuado ante actos de bullying (matoneo, acoso escolar) entre sus estudiantes.

- Explore algún caso en el que un estudiante se haya dado muerte a sí mismo. Indague cuál pudo ser el papel de la escuela y de los padres en dicho caso. ¿Cree que aun cuando padres y profesores cumplan con todas sus funciones, deberes y garantías, un niño puede sentir la necesidad darse muerte a sí mismo? 
Preguntas para debates grupales

- ¿Cómo puede un educador mantener sus límites, no abusar de su poder —autoridad- para dar privilegios a unos o rechazar a otros estudiantes? ¿Qué autocuidados debería tener?

- ¿Cómo puede el docente orientar el poder, su autoridad, para mediar y dirigir las competencias ciudadanas de un niño?

- ¿Cuándo el educador puede convertirse en factor de exclusión y agresión dentro de la escuela?

\section{Bibliografía básica}

Altarejos, F. y Naval, C. (2000). Filosofía de la educación. Pamplona: Eunsa.

Aluja, A., Del Barrio, V. y García, L. (2005). Relationships Between Adolescents' Memory of Parental Rearing Styles, Social Values and Socialisation Behaviour Traits. Personality and Individual Differences, 39(5), 903-912.

Baumrind, D. (1996). The Discipline Controversy Revisited. Family Relations, 45(4), 405-414.

Baumrind, D. (2005). Patterns of Parental Authority and Adolescent Autonomy. New Directions for Child and Adolescent Development, 108, 61-69.

Berzonsky, M. (2004). Identity Style, Parental Authority, and Identity Commitment. Journal of Youth and Adolescence, 33(3), 213-220.

Buri, J. (1991). Parental Authority Questionnaire. Journal of Personality Assesment, 57(1), 110-119.

Buxarrais, M. y Zeledón, M. (2006). ¿Por qué y para qué educar en valores desde el ámbito familiar? En M. Buxarrais y M. Zeledón (coords.), Las familias y la educación en valores democráticos: Restos y perspectivas actuales (pp. 159-183). Barcelona: Claret.

Carrington, V. (2002). New Times: New Families. Boston: Kluwer Academic Publishers.

Cava, M., Musitu, G. y Murgui, S. (2006). Family and School Violence: The Mediator Role of Self-Esteem and Attitudes Towards Institutional Authority. Psicothema, 18(3), 367-373.

Cooper, D. (1985). La muerte de la familia. Barcelona: Ariel.

Darling, N., Cumsille, P. y Peña-Alampay, L. (2005). Rules, Legitimacy of Parental Authority, and Obligation to Obey in Chile, the Philippines, and 
the United States. New Directions for Child and Adolescent Development, 108, 47-60.

Freud, S. (1979). Psicología del colegial. Buenos Aires: Amorrortu.

García de Ruiz, S. y García de Rubiano, A. (1980). Influencia de la autoridad familiar sobre la estructuración de los valores de los hijos. Revista Latinoamericana de Psicología, 12(3), 513- 520.

Mockus, A., Hernández, C., Granes, J., Cha-Rum, J. y Castro, M. (1994). Las frontera de la escuela. Bogotá: Sociedad Colombiana de Pedagogía.

Ríos, C. (1993). Violencia y relación pedagógica. Ponencia presentada en el I Seminario Taller Educación y Efecto Social, Universidad de Antioquia, Medellín, Colombia.

\section{Bibliografía complementaria}

Esteve, J. (1977). Autoridad, obediencia y educación. Madrid: Narcea.

Ferguson, E., Hagaman, J., Grice, J. y Peng, K. (2006). From Leadership to Parenthood: The Applicability of Leadership Styles to Parenting Styles. Group Dynamics-Theory Research and Practice, 10(1), 43-55.

Fuster, E. y Mositu, G. (2000). Psicología social de la familia. Barcelona: Paidós.

Jacquard, A. y Renaut, A. (2004). ¿Una educación sin autoridad ni sanción? Barcelona: Paidós.

Kovner, K. (2003). Hardwired to Connect: The New Scientific Case for Authoritative Communities. Report to the Nation from Commission on Children at Risk. Nueva York: Institute for American Values.

Manuel, L. (2006). Relationship of Personal Authoritarianism with Parenting Styles. Psychological Reports, 98(1), 193-198.

Mestre, M., Tur, A., Samper, P., Nácher, M. y Cortés, M. (2007). Rearing Styles in Adolescence: Their Relation with Prosocial Behaviour. Revista Latinoamericana de Psicología, 39(2), 211-225.

Musitu, G. y García, J. (2004). Consecuencias de la socialización familiar en la cultura española. Psicotema, 16(2), 288-293.

Renaut, A. (2007). School and Society: Crisis in Education. Revue Philosophique de Louvain, 105(1-2), 6-16.

Rossman, B. y Rea, J. (2005). The Relation of Parenting Styles and Inconsistencies to Adaptive Functioning for Children in Conflictual and Violent Families. Journal of Family Violent, 20(5), 261-277. 


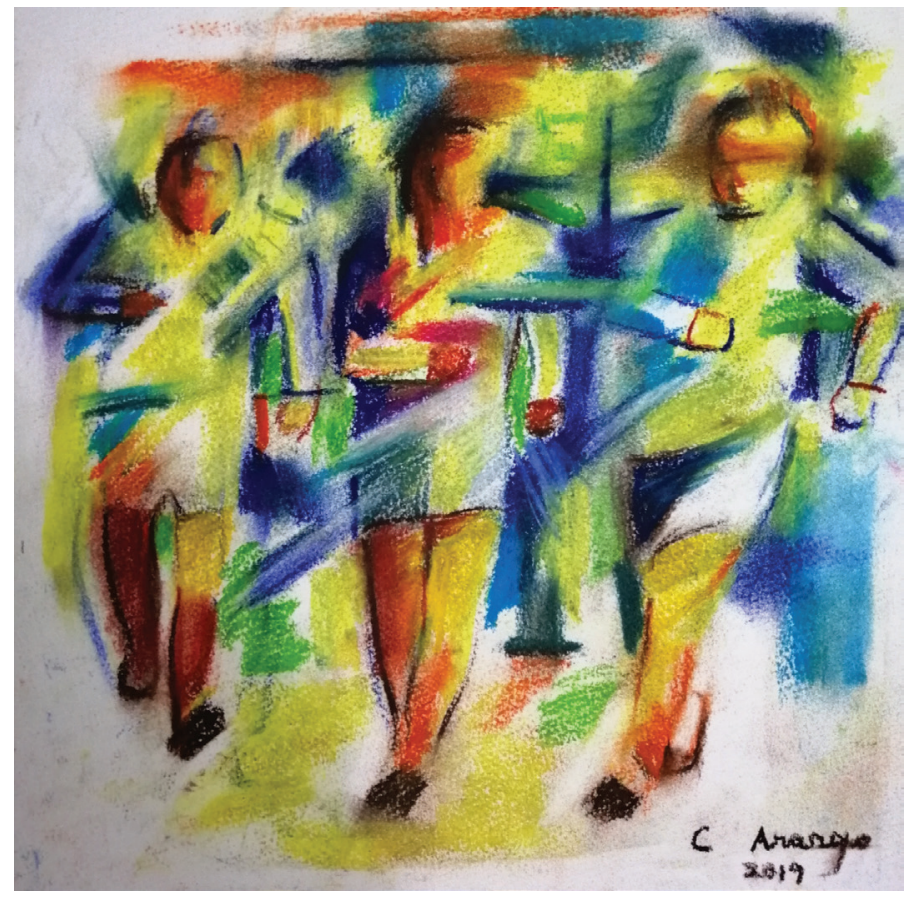

Cuando tenía a la niña grande metida en otro jardín, me le pegaban y me la mordian, y entonces tuvimos la oportunidad de meter a la niña acá en este jardín y me pareció bueno, porque es buena la atención, la atendian muy bien y lo atienden a uno también muy bien.

Madre de familia Hogar Infantil Fundehi, barrio El Arroyo, Cazucá, Soacha, 2017 